\title{
Behaviour influences cholesterol plasma levels in a pig model
}

\author{
W. M. Rauw ${ }^{1 \dagger}$, 0. Portolés ${ }^{2}$, D. Corella ${ }^{2}$, J. Soler ${ }^{3}$, J. Reixach ${ }^{4}$, J. Tibau ${ }^{3}$, J. M. Prat ${ }^{5}$, I. Diaz ${ }^{6}$ \\ and L. Gómez-Raya ${ }^{1}$
}

${ }^{1}$ Department of Animal Biotechnology, University of Nevada-Reno, Mail Stop 202, NV 89557, Reno, USA; ${ }^{2}$ Genetic and Molecular Epidemiology Unit, School of Medicine, University of Valencia, Valencia, Spain; ${ }^{3}$ IRTA, Centro de Control Porcino, 17121 Monells, Girona, Spain; ${ }^{4}$ Selección Batallé S.A., Riudarenes, Spain;

${ }^{5}$ Laboratori d'Analisis Clíniques, Hospital de Palamós, Palamós, Girona, Spain, ${ }^{6}$ IRTA, Centro de Tecnología de Carne, Monells, Girona, Spain

(Received 30 November 2006; Accepted 19 March 2007)

\begin{abstract}
Little is known about the relationship between feed intake behaviour and cholesterol levels in humans. This can be attributed to the fact that feed intake behaviour in humans is difficult to assess. The relationships between feed intake, feed efficiency and feed intake behaviour, and cholesterol and triglyceride levels were investigated at an average age of 187 days, in a pig model consisting of 202 Duroc barrows. Feed intake and feed intake behaviour were recorded individually and daily by means of an electronic identification system. Animals with high levels of total cholesterol also had high levels of high-density lipoprotein (HDL), low-density lipoprotein (LDL) cholesterol and triglycerides. Animals with high levels of HDL also had high levels of $L D L$ and triglycerides, and animals with high levels of $L D L$ also had high levels of triglycerides. Animals with higher $B W$, higher backfat thickness, higher BW gain, higher gain of backfat deposition, higher feed intake, higher residual feed intake (RFI) and higher feed intake rate had higher levels of total, HDL and LDL plasma cholesterol. Results indicate that the relationship between feed intake and cholesterol levels is a long-term relationship, while the relationship between RFI and cholesterol levels is more of a short-term nature. The relationship between intake rate and cholesterol plasma levels disappeared after correction for the amount of feed consumed. Results indicate that feed intake independent of metabolic BW, growth and fatness, i.e. 'RFI', was positively correlated with cholesterol plasma levels. This suggests that eating food over and above the maintenance and growth requirements constitutes a health risk independent of the level of fatness.
\end{abstract}

Keywords: cholesterol, feed intake behaviour, pig model, sire effect, triglyceride

\section{Introduction}

The effect of the diet on cholesterol levels and cardiovascular disease has been widely investigated (Stanner, 2006). However, little is known about the relationship between feed intake behaviour - such as total feed intake, intake rate, frequency and duration - and cholesterol levels in humans. This can be attributed to the fact that, in humans, feed intake behaviour is difficult to assess because it is influenced by a large variety of variables, such as physiological and genetic traits, psychological and socio-cultural factors, experiences, environmental conditions, and personal preferences, habits and sensitivities (De Castro, 1999).

The pig is considered to be the most suitable non-primate animal model since it resembles the human situation better than any other non-primate animal species with regard to eating behaviour, anatomy and physiology of the gastrointestinal tract (Davis et al., 2001). Also, the pig has

\footnotetext{
†E-mail: wrauw@cabnr.unr.edu
}

become increasingly accepted as an animal model for research on cholesterol and lipoprotein metabolism (Chapman and Goldstein, 1976; Pond and Mersmann, 1996).

In humans, the study of the relationship between food intake patterns and cholesterol levels mainly investigates situations in which food intake is related to obesity (e.g. Cordero-Maclntyre et al., 2000; Nicklas et al., 2001) and food intake patterns are related to food quality (e.g. Van Dam et al., 2003; Scaglioni et al., 2004). In animals, and farm animals, in particular, much research is directed to investigation of feed efficiency traits. A widely used estimate is that of 'residual feed intake (RFI)', which is defined as the feed that is consumed by an individual and its consumption as predicted from a model involving its maintenance and growth requirements (Luiting, 1990; Rauw et al., 2006a). Because of the complexity of measuring actual food intake in humans, this concept has never been applied to human research.

The aim of the present study is to investigate the relationship between feed intake behaviour and cholesterol and triglyceride plasma levels in a pig model. 


\section{Material and methods}

\section{Animals and experimental procedures}

Animals were provided by the company Selección Batallé (Riudarenes, Girona, Spain). The data set consisted a total of 202 Duroc barrows in two replicates (99 and 103 animals, respectively). Animals were born between August and September 2003 (replicate 1) and between March and April 2004 (replicate 2). Barrows were castrated sons of five sires $(17,34,40,42$ and 69 sons per sire, respectively) and 202 dams born on three farms $(60,69$ and 73 animals, respectively). Sire 1 had offspring in the first replicate only because he died before dams of the second replicate could be inseminated. There was no particular reason for the fact that sire 5 had almost twice as many offsprings as the others.

At weaning (11-23 days of age), pigs were moved to the test station 'Centre de Control Porci' (CCP-IRTA, Monells, Girona, Spain), distributed over 16 pens in four rooms and all were subjected to the same management procedures. At this stage, animals were housed based on age; animals that belonged to this experiment were mixed with animals that did not take part in this experiment, possibly of different breeds and sex.

Plasma cholesterol (total, high-density lipoprotein (HDL), and low-density lipoprotein (LDL) cholesterol) and triglyceride levels were measured once between 29 and 55 days of age ( $43 \pm 0.5$ days of age; TOTAL ${ }_{43}, \mathrm{HDL}_{43}, \mathrm{LDL}_{43}$ and $\mathrm{TRIG}_{43}$, respectively), and in the same individuals once between 171 and 201 days of age (187 \pm 0.6 days of age; TOTAL ${ }_{187}, \mathrm{HDL}_{187}, \mathrm{LDL}_{187}$ and $\mathrm{TRIG}_{187}$, respectively). At about 43 days of age, blood was collected from the jugular vein without fasting the animals. The second blood samples were taken at slaughter after the animals were fasted for over $12 \mathrm{~h}$.

Venous blood was collected into EDTA-containing tubes. Plasma total cholesterol and triglycerides were determined by a Technicon Chem 1 assay (Technicon Instruments, Tarrytown, NY), and HDL was measured in the supernatant after precipitation of apoB-containing lipoproteins with heparin-manganese chloride. The LDL concentration was calculated with the equation of Friedewald et al. (1972) as stated in Pond et al. (1997). Total plasma cholesterol includes HDL, LDL, intermediate-density lipoproteins, very low-density lipoproteins (VLDL) and chylomicrons, of which LDL constitutes the largest fraction and HDL the next largest fraction (Pond et al., 1993).

Between 2 and 3 months after birth, pigs participating in the present study were moved to the fattening and control unit where they were distributed over 10 pens (five pens at each side of a central corridor in the same barn) in groups of 8-12 animals. Approximately 2 weeks later and for 115 (replicate 1) and 118 (replicate 2) days, feed intake (Fl; kg/ day), intake time (TIME; min/day) and intake frequency (FREQ; visits/day) were recorded individually and daily by means of an electronic identification system (HOKOFARM, IVO-G ${ }^{\circledR}$; Marknesse, The Netherlands). The feeding station consisted of a single-space feed hopper, a trough which was weighted continuously and an electronic identification system that was activated by ear responders as the animal entered the station. The feeding station was connected through a load cell to a computer and the trough was refilled if the amount of feed left after a visit of a pig was completed was below $10 \mathrm{~kg}$. At each visit of a pig to the feeder, time and weight of the feed at the beginning and at the end of the visit were recorded automatically, together with the animal identification number. FI per visit was calculated as the difference between amounts recorded just before and after the visit, with an accuracy of $10 \mathrm{~g}$. Intake rate (RATE; $\mathrm{kg} / \mathrm{min}$ ) was estimated for each individual by dividing $\mathrm{Fl}$ by intake time. Intake rate is thus the amount of feed ingested per minute spent eating (Rauw et al., 2006b). On the 1st day of the feeding trial, animals were between 73 and 95 days of age.

Because of electricity failures, 24 recordings were missing in replicate 1 , and 16 in replicate 2 , spread out over the trial period. Missing values were estimated according to Rauw et al. (2006a). For the present study, FI traits were considered for the period between 170 and 175 days of age $\left(\mathrm{FI}_{170-175}, \mathrm{TIME}_{170-175}, \mathrm{FREQ}_{170-175}\right.$ and RATE $\left.{ }_{170-175}\right)$. This period was closest to the second age at which cholesterol and triglyceride levels were measured; data were available for 179 of the 202 barrows. Choosing a period at later ages would have decreased the number of animals considerably.

Until an average of 155 days of age, pigs were fed ad libitum on a standard diet with (per $\mathrm{kg}$ ) $180 \mathrm{~g}$ crude protein (CP), $38 \mathrm{~g}$ fibre, $70 \mathrm{~g}$ fat, $10 \mathrm{~g}$ lysine and $3 \mathrm{~g}$ methionine. Afterwards, animals were fed ad libitum on a standard diet with (per $\mathrm{kg}$ ) $151 \mathrm{~g} \mathrm{CP}, 45 \mathrm{~g}$ fibre, $49 \mathrm{~g}$ fat, $9 \mathrm{~g}$ lysine and $3 \mathrm{~g}$ methionine. The net energy concentration of the diets was 10290 and $9975 \mathrm{~kJ} / \mathrm{kg}$, respectively. Feed ingredients are given in Table 1. The amount of cholesterol in the feed was not specifically indicated. Only very small amounts would have been present because of the small amount of animal fat.

BW and backfat thickness (BFT) were recorded at the average age of $85,99,122,150,171$ and 189 days of age in replicate 1 and of 82,104,119,140,160 and 182 days of age in replicate 2. BFT was measured by the PIGLOG 105 A-mode apparatus (SFK Technology, Soborg, Denmark) as the average of two ultrasonic measurements taken on each side of the spinal column, $5 \mathrm{~cm}$ from the mid-dorsal line at the last rib. A linear regression equation was fitted individually to all six measurements on BW and BFT as a function of age, resulting in estimates of body-weight gain (BWG; $\mathrm{kg} /$ day) and rate of fat deposition (FATG; mm/day; Rauw et al., 2006b). The $R^{2}$ of the linear regression was 99.0 $( \pm 0.146 \%)$ for BW and $95.9( \pm 0.550 \%)$ for BFT (Rauw et al., 2006b). BW and BFT were estimated at 170 days of age from this linear regression ( $\mathrm{BW}_{170}$ and $\mathrm{BFT}_{170}$, respectively).

Individual RFI was estimated for the period between 170 and 175 days of age $\left(\mathrm{RFI}_{170-175}\right)$ from a multiple linear regression of $\mathrm{Fl}_{170-175}$ on estimated values of metabolic BW, BWG and BFT (Rauw et al., 2006a), for the 
Table 1 Main feed ingredients (2\% and higher) of the feed given up to an average of 155 days of age (Feed 1) and after this period (Feed 2)

$\%$

\begin{tabular}{lr}
\hline Feed 1 & \\
Barley & 30.0 \\
T Soja & 20.1 \\
Maize & 15.0 \\
Wheat & 11.9 \\
Fibre from rye & 10.0 \\
G Soja & 5.0 \\
Animal fat & 3.8 \\
Feed 2 & \\
Tapioca & 21.3 \\
Toasted soya meal & 18.4 \\
Peas & 13.9 \\
Barley & 13.4 \\
Rye & 8.9 \\
Maize & 5.0 \\
Wheat & 5.0 \\
Animal fat & 3.8 \\
Bran & 3.4 \\
Molasses & 2.8 \\
Beet pulp & 2.0 \\
\hline \hline
\end{tabular}

corresponding period:

$\mathrm{Fl}_{i}=b_{0}+\left(b_{1} \times \mathrm{BW}_{i}^{0.75}\right)+\left(b_{2} \times \mathrm{BWG}_{i}\right)+\left(b_{3} \times \mathrm{BFT}_{i}\right)+e_{i}$,

where $\mathrm{FI}_{i}=\mathrm{Fl}$ of individual $i\left(\mathrm{~kg} / 5\right.$ days), $\mathrm{BW}_{i}^{0.75}=$ average metabolic body weight of individual $i\left(\mathrm{~kg}^{0.75}\right), \mathrm{BWG}_{i}=\mathrm{BW}$ gain of individual $i$ (kg/5 days), $\mathrm{BFT}_{i}=$ average backfat thickness of individual $i(\mathrm{~mm}), b_{0}=$ population intercept, $b_{1}, b_{2}, b_{3}=$ partial regression coefficients representing maintenance requirements per metabolic $\mathrm{kg}$, feed requirements for growth and feed requirements related to body composition, respectively; $e_{i}=$ the error term, representing $\mathrm{RFI}$ of individual $i(\mathrm{~kg} /$ period). Metabolic BW and BFT were estimated as the average of the estimated values at the beginning and the end of the period between 170 and 175 days of age.

To investigate further the relationship between cholesterol measurements, and $\mathrm{FI}$ and $\mathrm{RFI}$, in addition, $\mathrm{FI}$ was summed and RFI estimated for the periods between 95 and 115, 115 and 135,135 and 155 and 155 and 175 days of age.

Blood sampling and the recording of feeding traits were approved by the Ethical Committee of the Institution (Institut de Recerca i Technologia Agroalimentàries).

\section{Statistical analysis}

The SAS program (Statistical Analysis Systems Institute, 1999) was used for statistical analysis of all traits. The model used to describe the data on TOTAL $\mathrm{L}_{43}, \mathrm{HDL}_{43}, \mathrm{LDL}_{43}$ and $\mathrm{TRIG}_{43}$ was

$Y_{i j k l m}=\mu+$ Sire $_{i}+\operatorname{Repl}_{j}+$ Farm $_{k}+\operatorname{PenW}(\text { Repl })_{l}+e_{i j k l m}$, where $\mu=$ population intercept, Sire $_{i}=$ effect of sire $i$ (1-5), Repl ${ }_{j}=$ effect of replicate $j(1,2)$, Farm $_{k}=$ effect of farm of origin $k(1-3)$, PenW(Repl) $)_{l}=$ effect of pen (until weaning; $1-16)$ nested within replicate $I_{1}$ and $e_{i j k / m}=$ residual error term of animal $m, e_{i j k l m} \sim \operatorname{NID}\left(0, \sigma_{\mathrm{e}}^{2}\right)$. All effects except the residual error term were considered fixed. The traits TOTAL ${ }_{43}, \mathrm{HDL}_{43}, \mathrm{LDL}_{43}$ and TRIG $\mathrm{G}_{43}$ were denoted by $Y_{i j k l m}$, as measured on animal $m$ of sire $i$, born in replicate $j$, originating from farm $k$, housed in pen $I$. Initially, also the effect of age at blood measurement was included in the model, but because this was not significant for any of the four traits, it was excluded from further analysis.

The model used to describe the data on TOTAL ${ }_{187}$, $\mathrm{HDL}_{187}, \mathrm{LDL}_{187}$ and TRIG 187 was

$$
Y_{i j k l}=\mu+\text { Sire }_{i}+\text { Repl }_{j}+\mathrm{AGE}_{k}+e_{i j k l},
$$

where $\mathrm{AGE}_{k}=$ age at second blood measurement, $e_{i j k l}=$ residual error term of animal $l_{1} e_{i j k l} \sim \operatorname{NID}\left(0, \sigma_{\mathrm{e}}^{2}\right)$, and $\mu_{\text {, }}$ $\mathrm{Sire}_{i}$ and $\mathrm{Repl}_{j}$ are as in model (2). All effects except the residual error term were considered fixed. The traits TOTAL $_{187}, \mathrm{HDL}_{187}, \mathrm{LDL}_{187}$ and TRIG 187 were denoted by $Y_{i j k l}$ as measured on animal $I$ of sire $i$, born in replicate $j$, measured at age $k$. Initially, also the effect of pen (fattening period) was included in the model, but because this was not significant for any of the four traits, it was excluded from further analysis.

The model used to describe the data on BW, BFT and FI behaviour was

$$
Y_{i j k l}=\mu+\text { Sire }_{i}+\operatorname{Repl}_{j}+\operatorname{PenF}(\operatorname{Repl})_{k}+e_{i j k l},
$$

where $\mu=$ population intercept, $\operatorname{PenF}(\operatorname{Repl})_{j}=$ effect of pen (fattening period; 1-10) nested within replicate $j, e_{i j k l}=$ residual error term of animal $m, e_{i j k l} \sim \operatorname{NID}\left(0, \sigma_{\mathrm{e}}^{2}\right)$, and Sire $_{i}$ and $\mathrm{Repl}_{j}$ are as in model (2). All effects except the residual error term were considered fixed. The traits tested under this model were denoted by $Y_{i j k l}$ as measured on animal / of sire $i$ born in replicate $j$, housed in pen $k$ : $\mathrm{BW}_{170 \text {, }}$ $\mathrm{BFT}_{170}, \mathrm{Fl}_{170-175}, \mathrm{RFI}_{170-175}, \mathrm{TIME}_{170-175}, \mathrm{FREQ}_{170-175}$, RATE $_{170-175}$, BWG and FATG. Initially, the effects of farm of origin and trial day were also included in the model, but because this was not significant for any of the nine traits, it was excluded from further analysis.

Phenotypic correlations were calculated after adjusting the values for the effects of replicate, farm and pen (TOTAL ${ }_{43}, \mathrm{HDL}_{43}, \mathrm{LDL}_{43}$ and $\mathrm{TRIG}_{43}$ ), for replicate and age at measurement (TOTAL ${ }_{187}, \mathrm{HDL}_{187}, \mathrm{LDL}_{187}$ and $\left.\mathrm{TRIG}_{187}\right)$, and for the effects of replicate and pen $\left(\mathrm{BW}_{170}, \mathrm{BFT}_{170}\right.$, $\mathrm{FI}_{170-175}, \mathrm{RFI}_{170-175}, \mathrm{TIME}_{170-175}, \mathrm{FREQ}_{170-175}, \mathrm{RATE}_{170-175}$, BWG and FATG).

\section{Results}

Table 2 presents mean values and standard errors for TOTAL $43, \mathrm{HDL}_{43}, \mathrm{LDL}_{43}, \mathrm{TRIG}_{43}, \mathrm{TOTAL}_{187}, \mathrm{HDL}_{187}, \mathrm{LDL}_{187}$, $\mathrm{TRIG}_{187}, \mathrm{BW}_{170}, \mathrm{BFT}_{170}, \mathrm{BWG}, \mathrm{FATG}, \mathrm{Fl}_{170-175}, \mathrm{RFI}_{170-175,}$ TIME $_{170-175,}$ FREQ $_{170-175}$ and RATE ${ }_{170-175}$. Phenotypic 
Rauw, Portolés, Corella, Soler, Reixach, Tibau, Prat, Diaz and Gómez-Raya

Table 2 Mean values and standard errors (s.e.) for total (TOTAL $\left.\mathrm{L}_{\mathrm{i}}\right)^{+}$, high-density lipoprotein $\left(H D L_{\mathrm{i}}\right)^{+}$and low-density lipoprotein $\left(L D L_{\mathrm{i}}\right)^{+}$ cholesterol and triglyceride levels $\left(T R I G_{\mathrm{i}}\right)^{\dagger}$, body weight $\left(B W_{\mathrm{i}}\right)^{\ddagger}$, backfat thickness $\left(B F T_{\mathrm{i}}\right)^{ \pm}$, body-weight gain $(B W G)^{\S}$, rate of fat deposition $(F A T G)^{\S}$, daily feed intake $\left(F_{i}\right)^{\prime \prime}$, residual feed intake $\left(R F I_{i}\right)^{\prime \prime}$, intake time $\left(T I M E_{\mathrm{i}}\right)^{\prime \prime}$, intake frequency $\left(F R E Q_{\mathrm{i}}\right)^{\prime /}$ and intake rate $\left(\text { RATE }_{\mathrm{i}}\right)^{\prime \prime}$

\begin{tabular}{lccl}
\hline \hline & $\mathrm{N}$ & Mean & \multicolumn{1}{c}{ s.e. } \\
\hline $\mathrm{TOTAL}_{43}(\mathrm{mg} / \mathrm{dl})$ & 202 & 78.3 & 0.965 \\
$\mathrm{HDL}_{43}(\mathrm{mg} / \mathrm{dl})$ & 202 & 31.3 & 0.453 \\
$\mathrm{LDL}_{43}(\mathrm{mg} / \mathrm{dl})$ & 202 & 39.4 & 0.605 \\
$\mathrm{TRIG}_{43}(\mathrm{mg} / \mathrm{dl})$ & 202 & 47.7 & 1.33 \\
$\mathrm{TOTAL}_{187}(\mathrm{mg} / \mathrm{dl})$ & 199 & 122.1 & 1.72 \\
$\mathrm{HDL}_{187}(\mathrm{mg} / \mathrm{dl})$ & 199 & 51.2 & 0.785 \\
$\mathrm{LDL}_{187}(\mathrm{mg} / \mathrm{dl})$ & 199 & 62.1 & 1.11 \\
$\mathrm{TRIG}_{187}(\mathrm{mg} / \mathrm{dl})$ & 199 & 56.0 & 1.78 \\
& & & \\
$\mathrm{BW}_{170}(\mathrm{~kg})$ & 179 & 105.2 & 0.912 \\
$\mathrm{BFT}_{170}(\mathrm{~mm})$ & 178 & 20.7 & 0.307 \\
$\mathrm{BWG}_{(\mathrm{g} / \mathrm{day})}$ & 190 & 889 & 9.41 \\
$\mathrm{FATG}_{(\mathrm{mm} / \mathrm{day})}$ & 186 & 0.185 & 0.00429 \\
$\mathrm{FI}_{170-175}(\mathrm{~kg} / \mathrm{day})$ & 179 & 3.22 & 0.0434 \\
$\mathrm{RFI}_{170-175}(\mathrm{~kg})$ & 179 & 0.00 & 0.0245 \\
$\operatorname{TIME}_{170-175}$ (min) & 179 & 61.8 & 1.03 \\
$\mathrm{FREQ}_{170-175}$ & 179 & 6.47 & 0.285 \\
$\mathrm{RATE}_{170-175}$ (kg/min) & 179 & 0.0538 & 0.000867 \\
\hline \hline
\end{tabular}

${ }^{\dagger}$ Measured at $i=$ an average of 43 and 187 days of age.

${ }^{\ddagger}$ Measured at $i=170$ days of age.

${ }^{\$}$ Measured for the entire feed intake trial.

"Measured between $i=170$ to 175 days of age.

correlations of cholesterol and triglyceride levels between the two measurements at different ages were low and not significant: $r=0.01$ and $P=0.936$ for total cholesterol, $r=0.05$ and $P=0.517$ for HDL cholesterol, $r=0.02$ and $P=0.813$ for LDL cholesterol, and $r=0.10$ and $P=0.172$ for triglyceride plasma levels.

Table 3 presents phenotypic correlations between TOTAL $43, \mathrm{HDL}_{43}, \mathrm{LDL}_{43}$ and $\mathrm{TRIG}_{43}, \mathrm{TOTAL}_{187}, \mathrm{HDL}_{187}$, $\mathrm{LDL}_{187}$, and $\mathrm{TRIG}_{187}$, and $\mathrm{BW}_{170}, \mathrm{BFT}_{170}, \mathrm{BWG}, \mathrm{FATG}$, $\mathrm{Fl}_{170-175,} \mathrm{RFI}_{170-175}, \mathrm{TIME}_{170-175}, \mathrm{FREQ}_{170-175}$ and RATE $170-175$. Animals with high levels of total cholesterol also had high levels of HDL, LDL and triglycerides. Animals with high levels of HDL also had high levels of LDL and triglycerides. Animals with high levels of LDL also had high levels of triglycerides (Table 3).

Table 3 shows a positive and highly significant phenotypic correlation between $\mathrm{BW}_{170}, \mathrm{BWG}, \mathrm{BFT}_{170}, \mathrm{FATG}$ $\mathrm{FI}_{170-175}, \mathrm{RFI}_{170-175}$ and RATE ${ }_{170-175}$ and TOTAL $187, \mathrm{HDL}_{187}$ and $\mathrm{LDL}_{187}$. The correlation was just not significant for the relationship between $\mathrm{RFI}_{170-175}$ and $\mathrm{HDL}_{187}$.

Table 4 presents phenotypic correlations between TOTAL $187, \mathrm{HDL}_{187}$ and $\mathrm{LDL}_{187}$ cholesterol and $\mathrm{FI}$ and RFI estimated for the periods between 95 and 115, 115 and 135, 135 and 155, and 155 and 175 days of age. The correlation between $\mathrm{Fl}$ and all cholesterol measurements were significantly positive in all periods. The correlation
Table 3 Phenotypic correlations between total $\left(\text { TOTAL }_{\mathrm{i}}\right)^{\dagger}$, high density lipoprotein $\left(H D L_{\mathrm{i}}\right)^{+}$and low-density lipoprotein $\left(L D L_{\mathrm{i}}\right)^{+}$cholesterol and triglyceride levels $\left(T R I G_{\mathrm{i}}\right)^{\dagger}$, and body weight $\left(B W_{\mathrm{i}}\right)^{*}$, backfat thickness $\left(B F T_{i}\right)^{*}$, body-weight gain (BWG) $)^{\S}$, rate of fat deposition (FATG) $)^{\S}$, daily feed intake $\left(F F_{i}\right)^{\prime \prime}$, residual feed intake $\left(R F I_{i}\right)^{\prime \prime}$, intake time $\left(T I M E_{\mathrm{i}}\right)^{\prime \prime}$, intake frequency $\left(F R E Q_{\mathrm{i}}\right)^{\prime \prime}$ and intake rate $\left(R A T E_{\mathrm{i}}\right)^{\prime \prime}$

\begin{tabular}{|c|c|c|c|c|}
\hline & TOTAL $_{43}$ & $\mathrm{HDL}_{43}$ & $\mathrm{LDL}_{43}$ & $\mathrm{TRIG}_{43}$ \\
\hline TOTAL $_{43}$ & & $0.80 * * *$ & $0.89 * * *$ & $0.48^{* * *}$ \\
\hline $\mathrm{LDL}_{43}$ & $0.89 * * *$ & $0.51 * * *$ & & $0.25^{* * *}$ \\
\hline \multirow[t]{2}{*}{$\mathrm{TRIG}_{43}$} & $0.48^{* * *}$ & $0.27^{*}$ & $0.25^{* * *}$ & \\
\hline & TOTAL $_{187}$ & $\mathrm{HDL}_{187}$ & $\mathrm{LDL}_{187}$ & TRIG $_{187}$ \\
\hline TOTAL $_{187}$ & & $0.82^{* * *}$ & 0.90 *** & $0.36^{* * *}$ \\
\hline $\mathrm{LDL}_{187}$ & $0.90 * * *$ & $0.52^{* * *}$ & & $0.19 * *$ \\
\hline TRIG $_{187}$ & $0.36^{* * *}$ & $0.17^{*}$ & 0.19 ** & \\
\hline $\mathrm{BW}_{170}$ & $0.31 * * *$ & $0.29 * * *$ & $0.30^{* * *}$ & -0.07 \\
\hline $\mathrm{BFT}_{170}$ & $0.50 * * *$ & $0.48^{* * *}$ & $0.43^{* * *}$ & 0.02 \\
\hline BWG & $0.36 * * *$ & $0.35^{* * *}$ & $0.33^{* * *}$ & -0.04 \\
\hline FATG & $0.47^{* * *}$ & $0.46^{* * *}$ & $0.40 * * *$ & 0.02 \\
\hline $\mathrm{Fl}_{170-175}$ & $0.43^{* * *}$ & $0.36^{* * *}$ & $0.41 * * *$ & 0.05 \\
\hline $\mathrm{RFI}_{170-175}$ & $0.23^{* *}$ & $0.14^{\top}$ & $0.24^{* *}$ & 0.09 \\
\hline TIME $_{170-175}$ & 0.12 & 0.08 & 0.11 & 0.10 \\
\hline $\mathrm{FREQ}_{170-175}$ & -0.11 & -0.09 & -0.09 & -0.07 \\
\hline RATE $_{170-175}$ & 0.22 ** & $0.19^{* *}$ & $0.22^{* *}$ & -0.04 \\
\hline
\end{tabular}

${ }^{\dagger}$ Measured at $i=$ an average of 43 and 187 days of age.

${ }^{\ddagger}$ Measured at $i=170$ days of age.

$\$$ Measured for the entire feed intake trial.

"Measured between $i=170$ and 175 days of age.

${ }_{P<0.10 \text {. }}$

Table 4 Phenotypic correlations between total $\left(\text { TOTAL }_{\mathrm{i}}\right)^{+}$, high-density lipoprotein $\left(H D L_{i}\right)^{+}$and low-density lipoprotein $\left(L D L_{i}\right)^{+}$cholesterol, and daily feed intake $\left(\mathrm{FI}_{\mathrm{i}}\right)^{\neq}$and residual feed intake $\left(\mathrm{RFI}_{\mathrm{i}}\right)^{\neq}$

\begin{tabular}{lcll}
\hline \hline & TOTAL $_{187}$ & $\mathrm{HDL}_{187}$ & $\mathrm{LDL}_{187}$ \\
\hline $\mathrm{Fl}_{95-115}$ & $0.20^{* *}$ & $0.17^{*}$ & $0.22^{* *}$ \\
$\mathrm{Fl}_{115-135}$ & $0.21^{* *}$ & $0.21^{* *}$ & $0.20^{* *}$ \\
$\mathrm{FI}_{135-155}$ & $0.35^{* * *}$ & $0.35^{* * *}$ & $0.31^{* * *}$ \\
$\mathrm{Fl}_{155-175}$ & $0.40^{* * *}$ & $0.35^{* * *}$ & $0.38^{* * *}$ \\
$\mathrm{RFI}_{95-115}$ & -0.03 & -0.02 & 0.02 \\
$\mathrm{RFI}_{115-135}$ & $0.13^{\S}$ & -0.09 & -0.11 \\
$\mathrm{RFI}_{135-155}$ & -0.01 & 0.01 & -0.01 \\
$\mathrm{RFI}_{155-175}$ & $0.16^{*}$ & 0.08 & $0.18^{*}$ \\
\hline \hline
\end{tabular}

${ }^{\dagger}$ Measured at $i=$ an average of 187 days of age.

${ }^{\ddagger}$ Measured between $i=95$ and 115, 115 and 135, 135 and 155, and 155 and 175 days of age.

${ }^{\S} P<0.10$.

between $\mathrm{RFI}$, and TOTAL $\mathrm{L}_{187}$ and $\mathrm{LDL}_{187}$ was significant for the period between 155 and 175 days of age only.

\section{Discussion}

As the relationship between $\mathrm{Fl}$ behaviour and cholesterol levels in humans is hard to measure accurately, the present 
study aimed at investigating the relationship between $\mathrm{FI}$ behaviour and cholesterol plasma levels in an animal model. Pigs have been used extensively in human nutrition research because they are similar in several key areas (Cooper et al., 1997; Darragh and Hodgkinson, 2000). They are monogastric, meal-eating, omnivorous mammals. The gastrointestinal anatomy, physiology and metabolism of the pig are very similar to those of the human (Moughan et al., 1994). Animals in the present study had ad libitum access to feed of a constant composition and quality, something that is hardly conceivable in human subjects.

\section{Validation of plasma lipids profile in a pig model}

Results of the present study showed that cholesterol and triglyceride plasma levels were higher at 187 days of age than at 43 days of age. This supports the observation that as animals mature, the amount of cholesterol in their tissues generally increases (Werdi Pratiwi et al., 2006). In our study, correlations between cholestrol and triglyceride measurements at about 43 and 187 days of age were low and not significant. In humans, the Busselton study provided a rare opportunity for longitudinal analysis of cholesterol tracking (Adams et al., 2005). Children were aged between 5 and 18 years when they attended a children's survey, and between 19 and 44 year at the adult surveys. The age- and survey-year-adjusted correlation coefficients ranged from 0.35 to 0.55 . To our knowledge, there is no study with repeated measurements in humans from weaning to maturity.

In the present study, total cholesterol concentration was highly significantly phenotypically related with LDL and HDL cholesterol concentrations. In humans a positive relationship between total and LDL cholesterol is observed also (Lam et al., 1990; Sun et al., 2000) which suggests that total cholesterol can be used as the initial screening to identify persons who may need lipoprotein analysis (Lam et al., 1990). Pond et al. (1993) observed in pigs selected for high total plasma cholesterol concentration at 8 weeks of age a positive phenotypic correlation between total and HDL cholesterol $(r=0.88)$; LDL concentration was not measured. They suggested that genetic selection for high total plasma cholesterol levels may thus be related more to changes in HDL cholesterol concentration than to changes in the LDL cholesterol fraction. Results of the present study suggest that this may not be the case.

In the present study, LDL and HDL cholesterol plasma levels were highly significantly positively correlated. A significant relationship between HDL and LDL cholesterol levels is observed in humans also, but this is observed to be negative (e.g. Fredenrich and Bayer, 2003; Olswold and De Andrade, 2003). This observation may be related to the divergence for lipoprotein metabolism across species (Pond and Mersmann, 1996). Compared with humans, in pigs there is a low synthesis of LDL from VLDL (Birchbauer et al., 1992), yet transfer of HDL-cholesterol esters to LDL occurs at a high rate in the pig (Terpstra et al., 1993). This observation may imply also differences between pigs and humans in health risk related to cholesterol levels. The meaning of this result for cholesterol research in pigs as a model for humans warrants further research.

In the present study, triglyceride plasma levels were (highly) positively phenotypically correlated with total, HDL and LDL cholesterol plasma levels (Table 3). This contradicts the suggestion by Pond et al. (1993) that triglyceride levels had no relationship to total or HDL cholesterol levels, 'indicating an independent mode of inheritance'. In humans, the relationship between triglyceride and HDL levels is found to be negative (Sprecher et al., 1994; Dobiasova and Frohlich, 2001).

\section{The relationship between fatness, body weight and cholesterol plasma levels in a pig model}

Results of the present study indicate that cholesterol and triglyceride plasma levels measured at 187 days of age were very highly positively related with BW at 170 days of age. In mice, Dunnington et al. (1981) observed an increased BW of females with selection for high total cholesterol concentrations. Furthermore, selection for high BW at 56 days of age was accompanied by an increase in total plasma cholesterol (Dunnington et al., 1981). In a divergent selection experiment for total plasma cholesterol at 56 days of age in pigs, average BW at birth and at 4 and 8 weeks of age were higher in the high line than in the low line; BW at 164 days of age did not differ significantly between the lines (Young et al., 1993). In the same selection experiment, Pond et al. (1993) observed high phenotypic correlations between 4- and 8-week BW and total cholesterol ( $r=0.44$ and 0.46 , respectively), HDL cholesterol ( $r=0.44$ and 0.46 , respectively) and triglyceride levels ( $r=0.26$ and $r=0.19$, respectively).

The present study shows a positive and highly significant correlation between cholesterol levels measured at about 187 days of age and BW gain in pigs. In the divergent selection experiment for cholesterol in pigs (Young et al., 1993), pigs from the high line grew $13 \%$ faster between birth and 4 weeks of age and $43 \%$ faster between 4 and 8 weeks of age, but growth rate was similar from 80 to 164 days of age. BW gain was positively correlated with total cholesterol concentration ( $r=0.46$; Pond et al., 1997). Little is known about the correlation between normal (non-obese) growth and cholesterol levels in humans. Mortaz et al. (2001) observed a higher cholesterol synthesis and lower cholesterol absorption efficiency in children who showed the greatest increase in weight centile between birth and 8-12 years of age, but only children born pre-term were considered in that study.

In the present study, the correlation between total, HDL and LDL levels at about 187 days of age, and BFT at about 170 days of age was positive and highly significant. Dunnington et al. (1977) observed a positive correlation between percent body fat and total plasma cholesterol in random-bred albino mice. In the divergent selection experiment in pigs, Harris et al. (2004) observed no differences between the high and the low cholesterol line in 
fat deposition at the first rib, 10th rib, last rib, or last lumbar vertebra. In the same experiment, Lu et al. (1995) observed a smaller BFT in high cholesterol line boars compared with low cholesterol line boars. In humans, people who are overweight generally have higher total and LDL cholesterol, lower HDL cholesterol and higher triglycerides (Hagan et al., 1983; Devroey et al., 2004; Wilsgaard and Arnesen, 2004).

The influence of Fl behaviour on cholesterol plasma levels In the present study, animals with higher $\mathrm{Fl}_{170-175}$ had higher cholesterol levels at 187 days of age. Feed intakes accumulated over four periods of 20 days between 95 and 175 days of age were all highly positively correlated with TOTAL ${ }_{187}, H L_{187}$ and $\mathrm{LDL}_{187}$. This may indicate a long-term relationship between cholesterol levels and FI. Also, animals with higher $\mathrm{RFI}_{170-175}$ had higher cholesterol levels at 187 days of age; the correlation with $\mathrm{HDL}_{187}$ tended to be significant. However, RFI estimated for three periods of 20 days between 95 and 155 days of age was not significantly correlated with any of the cholesterol measurements. Only the correlation for the period between 155 and 175 days of age was significantly correlated with $\mathrm{TOTAL}_{187}$ and $\mathrm{LDL}_{187}$. This may indicate a short-term relationship between feed efficiency and cholesterol levels only.

RFI as defined in the present study is an estimate of the amount of feed consumed adjusted for variation in metabolic BW, growth and fatness. The results indicate that animals that consumed feed over and above their expected requirements based on their metabolic BW, growth and level of fatness, had higher cholesterol levels. In the divergent selection experiment in pigs, no relationship was observed between $\mathrm{Fl}$ and feed efficiency between 90 and 164 days of age, and total cholesterol concentration at 8 weeks of age (Young et al., 1993). These results may support the fact that a relationship between feed efficiency and cholesterol levels is a short-term relationship only. No literature could be found referring to the relationship between food quantity intake (independent of food quality) or food efficiency, and cholesterol measurements in humans. As it would be practically unfeasible to measure food efficiency in humans eating food of one standard composition and quality, food efficiency in humans could alternatively be expressed in energy units.

In the present study, animals with a higher rate of FI had higher levels of cholesterol, but no relationship was observed between intake time or intake frequency, and cholesterol and triglyceride plasma levels. The effect of timing of $\mathrm{Fl}$ on metabolism has been the subject of active investigation in humans for over 40 years (Parks and McCrory, 2005). Variation in cholesterol synthesis appears to be strongly dependent on meal timing (Cella et al., 1995) and meal frequency (Gwinup et al., 1963; Jenkins et al., 1989; Titan et al., 2001; Farshchi et al., 2004). The question of whether there is a health benefit from the consumption of multiple small meals will ultimately depend on how much energy is consumed, as opposed to how often or how regularly one eats (Parks and McCrory, 2005). However, the association between meal frequency and plasma cholesterol in the study of Titan et al. (2001) was still present after adjustment was made for body mass index, physical activity, cigarette smoking and dietary intake. In the present study, adjusting cholesterol plasma levels and intake rate for the level of $\mathrm{Fl}$, did decrease the phenotypic correlations considerably, to $r=0.09,0.09$ and 0.10 for the correlation with total, $\mathrm{HDL}$ and $\mathrm{LDL}$ cholesterol, respectively; values were no longer significant. This indicates that the positive correlation between intake rate and cholesterol measurements were mainly a result of a correlated increase in FI.

To summarise, this study showed in a pig model that animals that were heavier, fatter, growing faster, with a higher rate of fat deposition, consuming more feed, at a higher rate, and being less feed efficient, had higher levels of total, HDL and LDL cholesterol. This study did not observe any relationship between intake time nor frequency and cholesterol plasma levels. Results indicate that the relationship between $\mathrm{Fl}$ and cholesterol levels is a long-term relationship, while the relationship between RFI and cholesterol levels is more of a short-term nature. The relationship between intake rate and cholesterol plasma levels disappeared after correction for the amount of feed consumed. Results indicate that Fl independent of metabolic BW, growth and fatness, i.e. 'RFI', was positively correlated with total and LDL cholesterol plasma levels and tended to be positively correlated with HDL cholesterol plasma levels. These results add a new dimension to the influence of food on cholesterol levels, as besides the influence of food quality and obesity as a result of overeating, the results suggests that eating food over and above the maintenance and growth requirements, but independent of the level of fatness, constitutes a health risk. The mechanism behind this relationship and its implications may be further investigated.

\section{Acknowledgements}

We are grateful to the Spanish Ministry of Science and Technology (MCYT) for financing this research through the Project AGL2002-04271-C03-02 entitled 'Arquitectura genética de los components lipídicos de la carne porcina relacionados con la calidad y la salud humana'. We are also very grateful to the company Selección Batallé for providing the Duroc pigs and for making this research possible.

\section{References}

Adams C, Burke V and Beilin $\mathrm{L}$ 2005. Cholesterol tracking from childhood to adult mid-life in children from the Busselton study. Acta Paediatrica (Oslo, Norway) 94, 275-280.

Birchbauer A, Wolf G and Knipping G 1992. Metabolism of very low density lipoproteins in the pig: an in vivo study. The International Journal of Biochemistry 24, 1591-1597.

Cella LK, Van Cauter E and Schoeller DA 1995. Effect of meal timing on diurnal rhythm of human cholesterol synthesis. American Journal of Physiology Endocrinology and Metabolism 32, E878-E883.

Chapman MJ and Goldstein S 1976. Comparison of the plasma low density lipoprotein and of its aproprotein in the pig, rhesus monkey and baboon with that in man. Atherosclerosis 25, 267-291. 
Cooper DA, Berry DA, Spendel VA, Kiorpes AL and Peters JC 1997. The domestic pig as a model for evaluating olestra's nutritional effects. The Journal of Nutrition 127, 1555S-1565S.

Cordero-Maclntyre ZR, Lohman TG, Rosen J, Peters W, Espana RC, Dickson B, Reidm PM, Howell WH and Fernandez ML 2000. Weight loss is correlated with an improved lipoprotein profile in obese postmenopausal women. Journal of the American College of Nutrition 19, 275-284.

Darragh AJ and Hodgkinson SM 2000. Quantifying the digestibility of dietary protein. The Journal of Nutrition 130, 1850S-1856S.

Davis SS, Illum L and Hinchcliffe M 2001. Gastrointestinal transit of dosage forms in the pig. The Journal of Pharmacy and Pharmacology 53, 33-39.

Devroey D, Vantomme K, Betz W and Vandevoorde J 2004. A review of the treatment guidelines on the management of low levels of high-density lipoprotein cholesterol. Cardiology 102, 61-66.

De Castro JM 1999. Behavioral genetics of food intake regulation in free-living humans. Nutrition (Burbank, Los Angeles County, CA) 15, 550-554.

Dobiasova $\mathrm{M}$ and Frohlich J 2001. The plasma parameter log (TG/HDL-C) as an atherogenic index: correlation with lipoprotein particle size and esterification rate in apoB-lipoprotein-depleted plasma (FERHDL). Clinical Biochemistry 34, 583-588.

Dunnington EA, White JM and Vinson WE 1977. Genetic parameters of serum cholesterol levels, activity and growth in mice. Genetics 85, 659-668.

Dunnington EA, White JM and Vinson WE 1981. Selection for serum cholesterol, voluntary physical activity, 56-day body weight and feed intake in random-bred mice: 2. Correlated responses. Canadian Journal of Genetics and Cytology 23, 545-555.

Farshchi HR, Taylor MA and Macdonald IA 2004. Regular meal frequency creates more appropriate insulin sensitivity and lipid profiles compared with irregular meal frequency in healthy lean women. European Journal of Clinical Nutrition 58, 1071-1077.

Fredenrich A and Bayer P 2003. Reverse cholesterol transport, high density lipoproteins and HDL cholesterol: recent data. Diabetes and Metabolism 29, 201-205.

Friedewald WT, Levy RI and Fredrickson DS 1972. Estimation of the concentration of low-density lipoprotein cholesterol in plasma without use of preparative ultracentrifuge. Clinical Chemistry 18, 4499-4502.

Gwinup G, Byron RC, Roush WH, Kruger FA and Hamwi GJ 1963. Effect of nibbling versus gorging on plasma lipids in man. The American Journal of Clinical Nutrition 13, 209-213.

Hagan RD, Smith MG and Gettman LR 1983. High density lipoprotein cholesterol in relation to food consumption and running distance. Preventive Medicine 12, 287-295.

Harris KB, Pond WG, Mersmann HJ, Smith EO, Cross HR and Savell JW 2004. Evaluation of fat sources on cholesterol and lipoproteins using pigs selected for high or low plasma cholesterol. Meat Science 66, 55-61.

Jenkins DJA, Wolever TMS, Vuksan V, Brighen F, Cunnane SC and Rao AV 1989. Nibbling versus gorging: metabolic advantages of increased meal frequency. The New England Journal of Medicine 321, 929-934.

Lam CLK, Munro C and Siu BPC 1990. A study of the correlation between serum total cholesterol and low-density lipoproteins (LDL) in Chinese. Family Practice 7, 301-306.

Lu CD, Pond WG, Mersmann HJ, Su D-R, Krook L, Harris JJ and Savell JW 1995. Response to dietary fat and cholesterol in young adult boars genetically selected for high or low plasma cholesterol. Journal of Animal Science 73 , 2043-2049.

Luiting P 1990. Genetic variation of energy partitioning in laying hens: causes of variation in residual feed consumption. Worlds Poultry Science Journal 46 , 133-152.

Mortaz M, Fewtrell MS, Cole TJ and Lucas A 2001. Birth weight, subsequent growth, and cholesterol metabolism in children 8-12 years old born preterm. Archives of Disease in Childhood 84, 212-217.

Moughan PJ, Cranwell PD, Darragh AJ and Rowan AM 1994. The domestic pig as a model for studying digestion in humans. In Digestive physiology in pigs (eds J Huisman, LA Den Hartog and MWA Verstegen), Proceedings of the Vth international symposium on digestive physiology in pigs, pp. 389-396. Wageningen Pudoc, The Netherlands

Nicklas TA, Baranowski T, Cullen KW and Berenson G 2001. Eating patterns, dietary quality and obesity. Journal of the American College of Nutrition 20, 599-608

Olswold C and De Andrade M 2003. Localization of genes involved in the metabolic syndrome using multivariate linkage analysis. BMC Genetics 4 , S57.

Parks EJ and McCrory ME 2005. When to eat and how often? The American Journal of Clinical Nutrition 81, 3-4.

Pond WG and Mersmann HJ 1996. Genetically diverse pig models for neonatal cholesterol nutrition: a review. Nutrition Research 16, 707-721.

Pond WG, Mersmann HJ, Klein PD, Ferlic LL, Wong WW, Hachey DL, Schoknecht PA and Zhang S 1993. Body weight gain is correlated with plasma cholesterol at 8 weeks of age in pigs selected for four generations for low or high plasma cholesterol. Journal of Animal Science 71, 2406-2411.

Pond WG, Su DR and Mersmann HJ 1997. Divergent concentrations of plasma metabolites in swine selected for 7 generations for high or low plasma total cholesterol. Journal of Animal Science 75, 311-316.

Rauw WM, Soler J, Tibau J, Reixach J and Gomez-Raya L 2006a. The relationship between residual food intake and food intake behavior in grouphoused Duroc barrows. Journal of Animal Science 84, 956-962.

Rauw WM, Soler J, Tibau J, Reixach J and Gomez-Raya L 2006b. Feeding time and feeding rate and its relationship with food intake, food efficiency, growth rate and rate of fat deposition in growing Duroc barrows. Journal of Animal Science 84, 3404-3409.

Scaglioni S, Veduci E, Agostoni C, Vergani B, Stival G, Riva E and Giovannini M 2004. Dietary habits and plasma fatty acids levels in a population of Italian children: is there any relationship? Prostaglandins, Leukotrienes and Essential Fatty Acids 71, 91-95

Sprecher DL, Hein MJ and Laskarzewski PM 1994. Conjoint high triglycerides and low HDL cholesterol across generations. Analysis of proband hypertriglyceridemia and lipid/lipoprotein disorders in first-degree family members. Circulation 90, 1177-1184.

Stanner S 2006. New thinking about diet and cardiovascular disease. Journa of Family Health Care 16, 71-74.

Statistical Analysis Systems Institute 1999. Release 6.1 edition. SAS Institute Inc, Care, NC

Sun P, Dwyer KM, Bairey Merz CN, Sun W, Johnson CA, Shircore AM and Dwyer JH 2000. Blood pressure, LDL cholesterol, and intima-media thickness. Arteriosclerosis Thrombosis and Vascular Biology 20, 2005-2010.

Terpstra AHM, Stucchi AF, Foxall TL, Shwaery GT, Vespa DB and Nicolosi RJ 1993. Unidirectional transfer in vivo of high-density lipoprotein cholesteryl esters to lower-density lipoproteins in the pig, an animal species without plasma cholesteryl ester transfer activity. Metabolism 42, 1524-1530.

Titan SMO, Bingham S, Welch A, Luben R, Oakes S, Day N and Khaw KT 2001 Frequency of eating and concentrations of plasma cholesterol in the Norfolk population of the European prospective investigation into cancer (EPICNorfolk): cross sectional study. BMJ 323, 1-5.

Van Dam RM, Grievink L, Ocke MC and Feskens EJM 2003. Patterns of food consumption and risk factors for cardiovascular disease in the general Dutch population. American Journal of Clinical Nutrition 77, 1156-1163.

Werdi Pratiwi NM, Murray PJ and Taylor DG 2006. Total cholesterol concentrations of the muscles in castrated Boer goats. Small Ruminant Research 64, 77-81.

Wilsgaard T and Arnesen E 2004. Change in serum lipids and body mass index by age, sex, and smoking status: the Tromso study 1986-1995. Annals Epidemiology 14, 265-273.

Young LD, Pond WG and Mersmann HJ 1993. Direct and correlated responses to divergent selection for plasma cholesterol concentration on $\mathrm{d} 56$ in swine Journal of Animal Science 71, 1742-1753. 